University of Texas at El Paso

\title{
DigitalCommons@UTEP
}

Open Access Theses \& Dissertations

2010-01-01

\section{Impact of Moisture Content and Density on Stiffness-Based Acceptance of Geomaterials}

Lourdes Guadalupe Pacheco

University of Texas at El Paso, lgpacheco@miners.utep.edu

Follow this and additional works at: https://digitalcommons.utep.edu/open_etd

Part of the Civil Engineering Commons, and the Geotechnical Engineering Commons

\section{Recommended Citation}

Pacheco, Lourdes Guadalupe, "Impact of Moisture Content and Density on Stiffness-Based Acceptance of Geomaterials" (2010). Open Access Theses \& Dissertations. 2747.

https://digitalcommons.utep.edu/open_etd/2747 


\section{IMPACT OF MOISTURE CONTENT AND DENSITY ON STIFFNESS-BASED ACCEPTANCE OF GEOMATERIALS}

LOURDES GUADALUPE PACHECO FERNANDEZ

Department of Civil Engineering

APPROVED:

Soheil Nazarian, Ph.D., Chair

Vivek Tandon, Ph.D.

Diane Doser, Ph.D.

Patricia D. Witherspoon, Ph.D.

Dean of the Graduate School 


\section{Copyright $($ )}

by

Lourdes G. Pacheco F.

2010 


\section{Dedication}

To My Family

2010 


\title{
IMPACT OF MOISTURE CONTENT AND DENSITY ON STRENGTH AND STIFFNESS
}

\author{
by
}

LOURDES GUADALUPE PACHECO FERNANDEZ, BSCE, EIT

\section{THESIS}

Presented to the Faculty of the Graduate School of The University of Texas at El Paso

$$
\begin{aligned}
& \text { in Partial Fulfillment } \\
& \text { of the Requirements } \\
& \text { for the Degree of }
\end{aligned}
$$

MASTER OF SCIENCE

Department of Civil Engineering

THE UNIVERSITY OF TEXAS AT EL PASO

May 2010 


\section{Acknowledgements}

The author would like to express her gratitude to Dr. Soheil Nazarian, Director of Center for Transportation Infrastructure Systems and Professor of Civil Engineering at the University of Texas at El Paso for his guidance during the course of this study.

Thanks are also due to Dr. Vivek Tandon, Professor of Civil Engineering and Dr. Diane Doser Professor of Geology Department, for their participation in the final examination of the author.

The author would also like to express her gratefulness for the unconditional support of her family. Specially her parents Mr. Enrique Pacheco and Mrs. Altagracia Fernandez for their support, tolerance, encouragement, and patience to the author throughout this study.

Above all the author thanks God without whom this study would not have been completed. 


\begin{abstract}
Modulus-based quality management of compacted layers has been considered by a number of highway agencies. Even though simple in concept, the paradigm shift from density to modulus for quality acceptance has generated some technical and institutional challenges. One of these complications is that for a given density, the modulus can vastly vary depending on the moisture content at the time of compaction and at the time of acceptance. The results of a systematic study carried out to qualify and quantify the impact of compaction moisture content, moisture content at the time of field testing and density on the modulus and strength of four diverse geomaterials. It was found that for specimens compacted to the maximum dry density but with 2 to $3 \%$ variation in compaction moisture contents, the changes in modulus at the time of acceptance can vary by a factor of five or more depending on the index properties of a given material. These changes are further exaggerated as the time between the compaction and field acceptance increases. Also specifying densities less than maximum dry densities have significant impact on the modulus of the material at the time of acceptance. These issues should be incorporated in the modulus-based specifications to maximize the potential for the shift from the less desirable density-based acceptance to more sound modulus-based approach.
\end{abstract}




\section{Table of Contents}

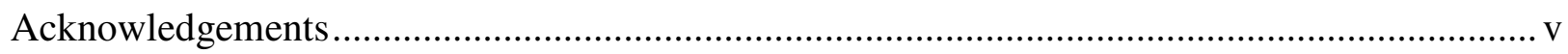

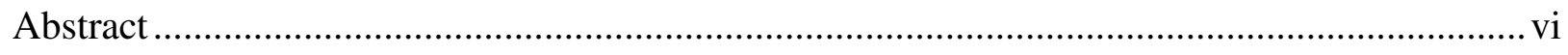

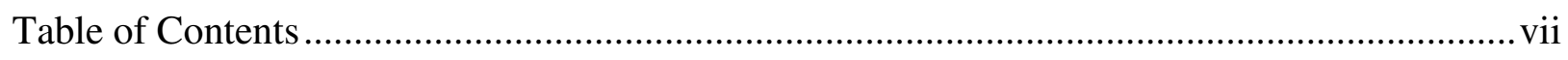

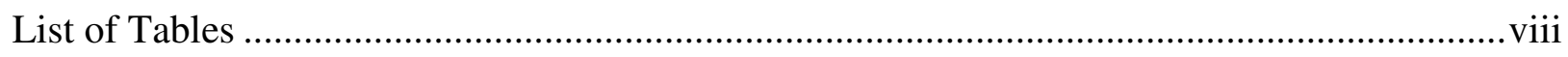

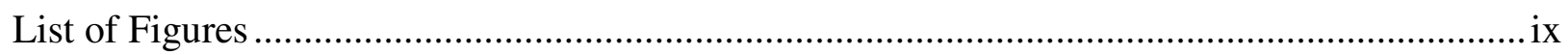

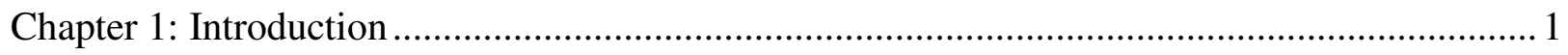

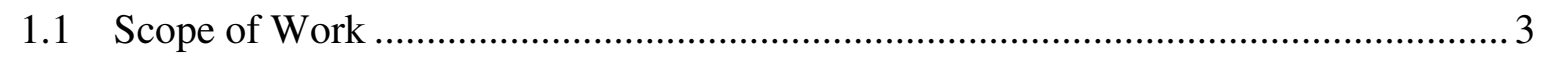

Chapter 2: Preliminary Evaluation of Materials Used .................................................... 4

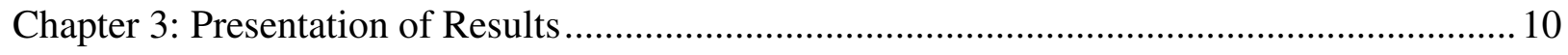

3.1 Impact of Moisture at Time of Compaction ....................................................... 10

3.2 - Impact of Moisture at Time of Acceptance relative to Moisture at Compaction ...... 11

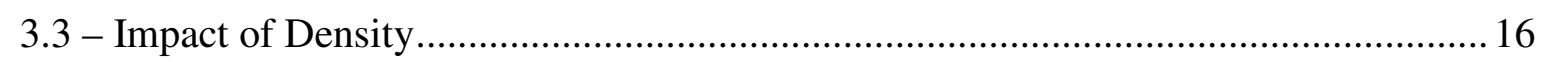

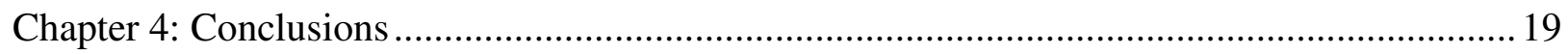

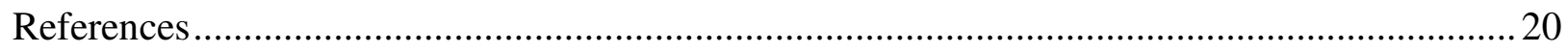

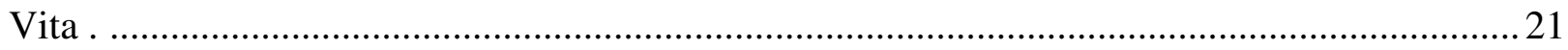




\section{List of Tables}

Table 2.1 - Summary of Index Properties of the Geomaterials Used in this Study...................... 4

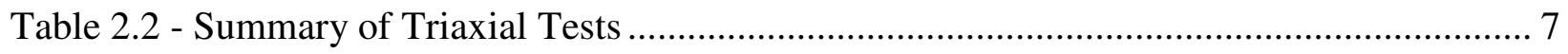

Table 2.3 - Moisture Content, Dielectric, Modulus, and UCS variations................................... 8 


\section{List of Figures}

Figure 2.1 - Free-Free Resonant Column System................................................................. 5

Figure 2.2 - Moisture Density and Strength Curves of the Geomaterials Used in this Study ….... 6

Figure 2.3 - Tube Suction Test Results of the Geomaterials Used in this Study........................... 9

Figure 3.1 - Number of drops vs. moisture content variation comparison.................................... 11

Figure 3.2 - Impact of Moisture Variation on Modulus and Strength at time of Compaction ..... 12

Figure 3.3 - Modulus and Strength Variation at Time of Acceptance for Clay Material ............ 14

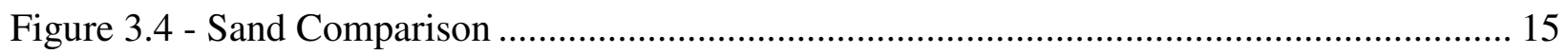

Figure 3.5 - Modulus and Strength Variation at Time of Acceptance for High-Fine Base ......... 15

Figure 3.6 - Modulus and Strength Variation at Time of Acceptance for Low-Fine Base .......... 16

Figure 3.7- Number of drops comparison for the Geomaterials Used in this Study ................... 17

Figure 3.8 - Impact on Modulus and Strength with Density Variation for the Geomaterials Used

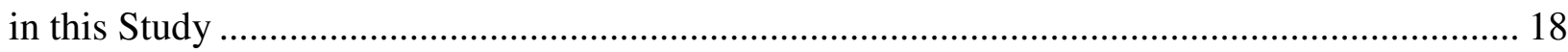




\section{Chapter 1: Introduction}

The performance of a pavement depends on many factors such as the structural adequacy of the pavement, the properties of the materials used, traffic loading, climatic conditions and the construction method. Previous research has found that much of the distress in flexible pavements can be traced to problems encountered in the quality of base and subgrade (NCHRP, 2000). The performance of a pavement can only be assured with appropriate process control (to ensure the material used is similar to that selected), proper processing of the material (to ensure that the material is uniformly mixed and contains appropriate amount of moisture before compaction) and adequate compaction equipment (to ensure proper density/stiffness). The primary parameter for quality acceptance is the appropriate density with a nuclear density gauge (NDG). Despite the importance of the moisture content at the time of compaction (Puppala, 2008), a number of highway agencies have not included moisture content in their specifications. With the recent popularity of mechanistic pavement design procedures, devices that can provide the modulus of compacted layers have become popular. Much work has been performed in regard to modulusbased quality control of compacted geomaterials (e.g., Nazarian et al., 2003a; Abu-Farsakh et al., 2004; Petersen et al., 2007). In-situ test devices have been studied to determine the pavement layer moduli (e.g., Alshibli et al., 2005; Von Quintus et al., 2009). These devices include Portable Falling Weight Deflectometer (PFWD a.k.a. LWD), Dynamic Cone Penetrometer (DCP), Geogauge, Portable Seismic Pavement Analyzer (PSPA), and Briaud compaction device (BCD). Von Quintus et al. (2009) indicated that the rate of success of density-based measurements in locating construction defects was only $25 \%$, while the modulus-based methods exhibited 64 to $86 \%$ rate of success. 
Even though simple in concept, the paradigm shift from density to modulus for quality acceptance has generated some technical and institutional complications. Two complicating factors are how to set the target modulus for field testing and how to set the modulus tolerances for acceptance. The target modulus should be preferably set based on laboratory tests in conjunction with establishing the modulus for structural design (Nazarian et al., 2003a). Alternatively, the target modulus is set based on field test strips as done in current $\mathrm{Mn} / \mathrm{DOT}$ protocol. Some of the complications on this subject are the following:

The states of the stress during pavement design due to truck traffic and under the modulus field test device are different. The target field modulus should be established by considering the dimensions and typical load applied by the device, the lift thickness and the moduli of underlying layers.

For the same density, the laboratory compaction energy may not be representative of the field compaction energy, especially given the inevitable variation in moisture and compaction energy during construction.

Even though the design modulus is based on the long-term behavior, the target modulus is based on the short term behavior (say the first $24 \mathrm{hrs}$ after compaction) to minimize delay in construction. The short-term modulus of exposed compacted geomaterials may vary significantly due to loss of moisture and "curing" (thixotropic gain in stiffness).

The variation in modulus with moisture is currently estimated by changing the moisture content of the laboratory specimens during compaction. In a proper field compaction, the geomaterial is placed near the optimum moisture content and the moisture change is due either evaporation or the introduction of moisture. The moduli obtained from these two processes at a 
given moisture content can be vastly different (Khoury and Zaman, 2004 and Sabnis et al., 2009).

The goal of this study is to address the third and fourth items, even though the first two items are also extremely important.

\subsection{Scope of Work}

The primary objectives of this study are to present the impact of moisture at the time of compaction on the performance of the materials, the impact of moisture at the time of acceptance testing relative to the moisture at the time of compaction on the final quality of the base/subgrade, and the impact of acceptance density relative to the maximum dry density.

To achieve these objectives, four different geomaterials with different characteristics (clay, sand, low-fine content granular base and high-fine content granular base) were selected and subjected to a number of strength and stiffness tests. To study the impact of the moisture content at the time of compaction, a number of specimens were prepared from each material to its maximum density but at different moisture contents by changing the compactive effort. After 24 hours, change in dimensions and modulus were measured, previous to be subjected to UCS. To evaluate the impact of moisture at time of acceptance relative to moisture at compaction, several specimens were prepared from each material to its maximum density but at different moisture contents and allowing them to dry to moisture contents dry of OMC. The loss in moisture, change in dimensions, and modulus were monitored regularly. Finally, to study the impact of density, several specimens from each material were prepared at OMC and relative densities of $98 \%$ and $96 \%$, after 24 hours, change in dimensions and modulus were measures previous to be subjected to UCS 


\section{Chapter 2: Preliminary Evaluation of Materials Used}

Three materials were selected to generate a baseline for verification of the outcomes of this study. The three geomaterials were a clayey material from Austin, TX, a sandy material from Bryan, TX and a granular base from El Paso, TX. Table 2.1 presents a summary of the index properties for all materials used in this study including the optimum moisture contents (OMC) and maximum dry densities (MDD). The two subgrade soils (clay and sand) are vastly different. The only difference between the two bases is the gradation. The high-fine-content (HF) base conforms to the traditional specifications of the Texas Department of Transportation (TxDOT) while the low-fine content (LF) base conforms to the recently improved specifications of TxDOT.

Table 2.1 - Summary of Index Properties of the Geomaterials Used in this Study

\begin{tabular}{|c|c|c|c|c|c|c|c|c|c|c|}
\hline \multirow[b]{2}{*}{ Soil } & \multicolumn{4}{|c|}{ Gradation \% } & \multirow{2}{*}{$\begin{array}{c}\text { USCS } \\
\text { Classification }\end{array}$} & \multicolumn{3}{|c|}{ Atterberg Limits } & \multicolumn{2}{|c|}{ Moisture Density } \\
\hline & Gravel & Sand & Silt & Clay & & $\mathbf{L L}$ & PL & PI & OMC, $\%$ & $\begin{array}{l}\text { MDD, } \\
\mathbf{k g} / \mathbf{m}^{3}\end{array}$ \\
\hline Clay & 0 & 13 & 40 & 47 & CL & 45 & 14 & 31 & 20.9 & 1637 \\
\hline Sand & 1 & 53 & 18 & 28 & $\mathrm{SC}$ & -- & -- & $\mathrm{N} / \mathrm{P}$ & 10.4 & 1991 \\
\hline HF Base & 63 & 12 & 17 & 8 & GW-GC & 27 & 19 & 8 & 6.7 & 2300 \\
\hline LF Base & 73 & 11 & 11 & 5 & $\mathrm{GW}$ & 27 & 19 & 8 & 6.2 & 2341 \\
\hline
\end{tabular}

The moisture-density relationships for the Clay and Sand were determined as per Tex114-E which is similar to ASTM D698 and for the two bases based on Tex-113-E which uses slightly less energy than the ASTM D1557. The specimens prepared for this activity where wrapped in cellophane for $24 \mathrm{hrs}$ to minimize moisture loss and then tested with a Free-Free Resonant Column (FFRC, ASTM C215) device for modulus and unconfined compressive strength (UCS, ASTM D2166). The FFRC test, which measures the low-strain modulus of a 
specimen; it is based on detecting the fundamental mode resonant frequencies of vibration of a specimen. As an impulse load is applied to a cylindrical specimen, seismic energy over a large range of frequencies will transmit through the specimen (Nazarian et al., 2003b). The main components in the setup of the test and the procedure of testing are shown in Figure 2.1. An accelerometer is securely placed on top of the specimen, and the specimen is impacted with a hammer instrumented with a load cell. Once the resonant frequency, $\mathrm{f}_{\mathrm{L}}$, and the length of the specimen, L, are known, Young's modulus, E, can be found from the following relation:

$$
E=\rho\left(2 f_{L} L\right)^{2},
$$

where $\rho$ is mass density.
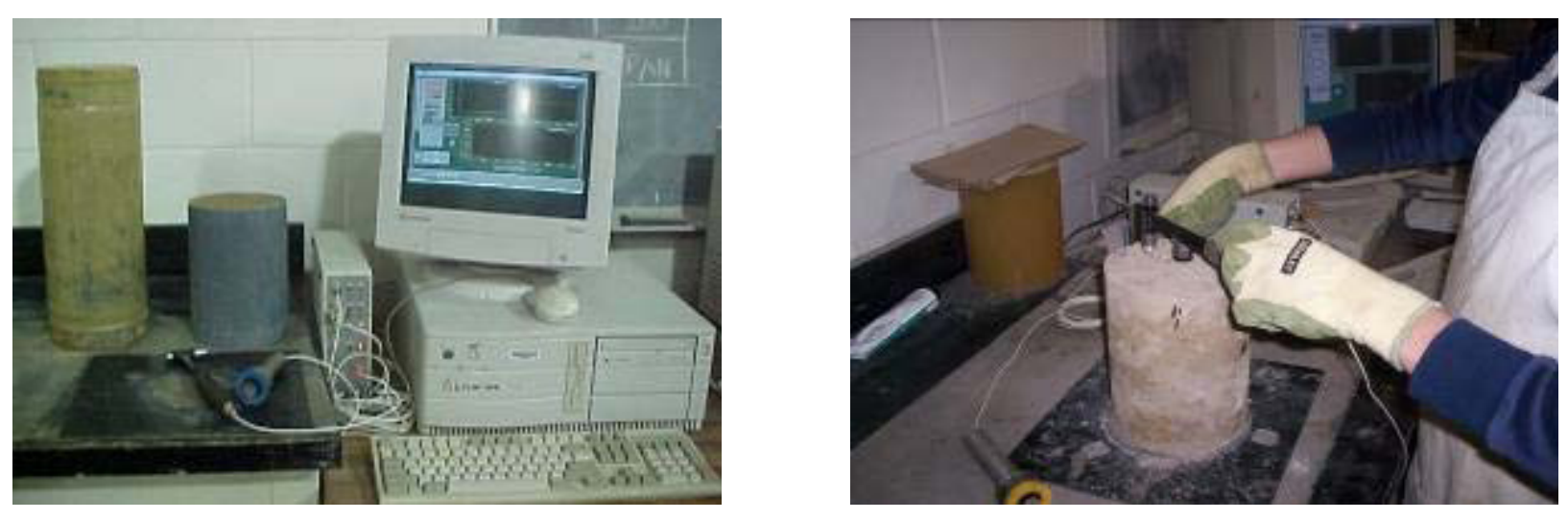

Figure 2.1 - Free-Free Resonant Column System

The moisture-density curves for the four materials along with the moisture modulus/ strength relationships are also shown in Figure 2.2. In our opinion, the additional strength parameters can be used to judge the sensitivity of a material to moisture content. The changes in dry densities in the ranges of moisture contents of $\mathrm{OMC} \pm 2 \%$ for the four materials are at the most $4.4 \%$ of the corresponding MDDs, while the moduli and strength variations around the same moisture content ranges are more than $40 \%$ of the corresponding moduli and strengths at 

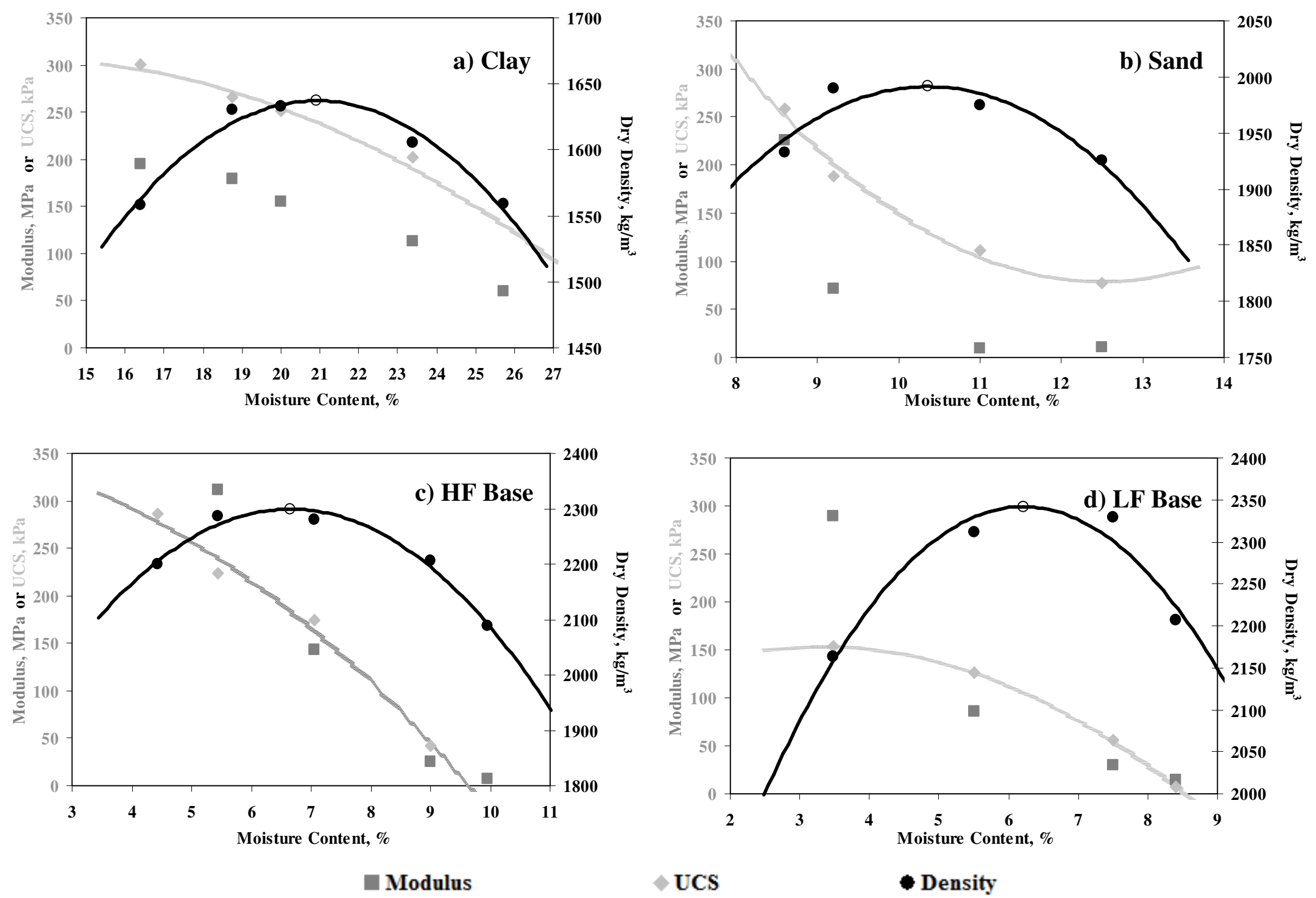

Figure 2.2 - Moisture Density and Strength Curves of the Geomaterials Used in this Study 
the corresponding OMC's. The moduli and strengths of the materials are significantly lower when the specimens are prepared wet of respective OMC's; especially for the sand and base materials. This reflects the practical importance of checking the moisture content in the field before allowing the compaction of the geomaterials to obtain a reasonable strength and stiffness, and the lack of sensitivity of density to the quality of the compacted layer.

The shear strength parameters of each material on specimens prepared at the OMC and MDD are presented in Table 2.2. Two sets of parameters are demonstrated, one for specimens that were moisture conditioned with capillary saturation for ten days and the second for specimens tested without moisture conditioning. As per Table 2.2, the Clay material is the most susceptible material to moisture followed by the Sand material. The increase in angle of internal friction for the base material, high-fine and low-fine, reflects the lack of moisture at the top of the specimen since this material is not moisture susceptible as the clay material.

Table 2.2 - Summary of Triaxial Tests

\begin{tabular}{|c|c|c|c|c|c|c|c|c|}
\hline \multirow{2}{*}{ Parameter } & \multicolumn{8}{|c|}{ Test Method } \\
\cline { 2 - 9 } & \multicolumn{2}{|c|}{ Moisture Conditioned Specimens } & \multicolumn{3}{c|}{ Standard Specimens } \\
\hline Material & Clay & Sand & $\begin{array}{c}\text { HF } \\
\text { Base }\end{array}$ & $\begin{array}{c}\text { LF } \\
\text { Base }\end{array}$ & Clay & Sand & $\begin{array}{c}\text { HF } \\
\text { Base }\end{array}$ & $\begin{array}{c}\text { LF } \\
\text { Base }\end{array}$ \\
\hline $\begin{array}{c}\text { Angle of Internal } \\
\text { Friction, degree }\end{array}$ & 0.0 & 34.8 & 22.0 & 53.8 & 22.4 & 43.2 & 10.0 & 40.2 \\
\hline Cohesion, c, kPa & 21 & 31 & 34 & 0 & 218 & 31 & 82 & 38 \\
\hline
\end{tabular}

The next step of the preliminary evaluation consisted of simulating the changes in stiffness of the materials due to change in moisture content. For this purpose, specimens from each material were molded at the corresponding OMC and MDD, placed in a $40^{\circ} \mathrm{C}$ oven for two days, and then placed on porous stones soaked in a pan of water for capillary moisture 
conditioning for eight days. Over the course of these ten days, the moduli with the FFRC tests and the dielectric values with a Percometer (as described in Scullion and Saarenketo, 1997) were measured daily. In addition the specimens were weighted every day to determine the variations in bulk moisture content with time. Typical variations in dielectric constant, moisture content and seismic modulus for all materials used in this study are shown in Figure 2.3, and the results are summarized in Table 2.3. Clay material is the most susceptible to moisture. For the sand material the strength change is minimum. Base materials are not affected by moisture; the water is absorbed and retained in the bottom $5 \mathrm{~cm}$ of the specimen.

Table 2.3 - Moisture Content, Dielectric, Modulus, and UCS variations

\begin{tabular}{|c|c|c|c|c|c|}
\hline \multirow{3}{*}{ Parameter } & \multirow{2}{*}{ Condition } & \multicolumn{4}{|c|}{ Material } \\
\cline { 3 - 6 } & & Clay & Sand & HF Base & LF Base \\
\hline \multirow{3}{*}{$\begin{array}{c}\text { Moisture } \\
\text { Content, \% }\end{array}$} & Day 0 & 20.7 & 10.6 & 7.0 & 6.1 \\
\cline { 2 - 6 } & Day 2 & 8.5 & 2.6 & 2.6 & 2.1 \\
\cline { 2 - 6 } & Day10 & 20.8 & 10.3 & 4.4 & 3.3 \\
\hline \multirow{3}{*}{ Dielectric } & Day 0 & 21.4 & 11.7 & 14.0 & 11.8 \\
\cline { 2 - 6 } & Day 2 & 8.5 & 3.4 & 5.6 & 5.2 \\
\cline { 2 - 6 } Modulus, & Day10 & 9.6 & 12.2 & 5.0 & 4.6 \\
\cline { 2 - 6 } MPa & Day 0 & 142.7 & 19.4 & 71.7 & 21.3 \\
\cline { 2 - 6 } & Day 2 & 928.1 & 2896.6 & 2219.4 & 2086.0 \\
\cline { 2 - 6 } & Day10 & 16.8 & 24.3 & 197.9 & 266.6 \\
\hline \multirow{3}{*}{ UCS, kPa } & Day 0 & 314 & 154 & 166 & 140 \\
\cline { 2 - 6 } & Day 2 & N/A & N/A & N/A & N/A \\
\cline { 2 - 6 } & Day10 & 17 & 126 & 189 & 168 \\
\hline
\end{tabular}



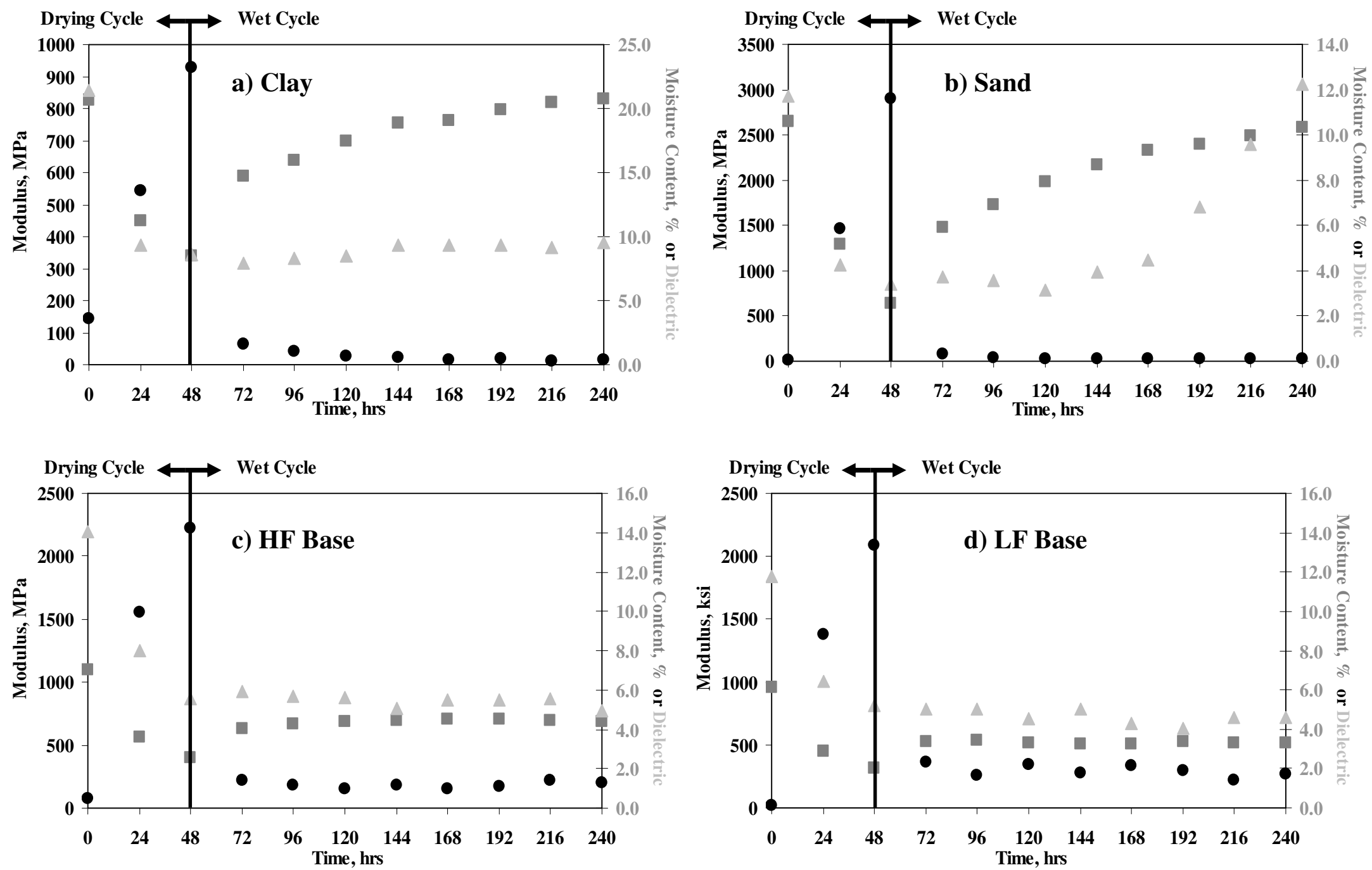

- Modulus

Moisture

$\triangle$ Dielectric

Figure 2.3 - Tube Suction Test Results of the Geomaterials Used in this Study 


\section{Chapter 3: Presentation of Results}

In this chapter the parametric study for this project is presented.

\subsection{Impact of Moisture at Time of Compaction}

To quantify the variation in strength parameters of the material as a function of the compaction moisture content, several specimens from each material were prepared at varying moisture contents $(\mathrm{OMC} \pm 1.5 \%$ and $\mathrm{OMC} \pm 3 \%$ for Clay, and $\mathrm{OMC} \pm 1 \%$ and $\mathrm{OMC} \pm 2 \%$ for Sand and two granular bases). Irrespective of the moisture content, all specimens were compacted to their corresponding target MDDs when possible by adjusting the compaction energy through trial and error. The variations in the number of hammer drops as a function of mixing moisture contents are presented in Figure 3.1 for the Sand and two base materials. Since the Clay specimens for this part of study were compacted with a static compactor, such information is not available. The number of hammer drops as a function of moisture content for the Sand shows a linear trend with the number of blows for specimens prepared dry of optimum is less than that at the OMC. The main reason for this matter, aside from experimental error is the fat that the dry density is not sensitive to the moisture content at all. As reflected in Figure 2.2d, the change of moisture between $8.5 \%$ and $12.5 \%$ will change the dry density by only $3 \%$. Given the scatter in the data in Figure 2.2, the OMC can readily fall anywhere between 9 and 11\%. For the two base materials, the highest dry densities that could be achieved for the specimens at OMC-2\% were about $98 \%$ and $97 \%$ of MDD for 90 drops. The hammer drops were limited to 90 because of excessive crushing of the materials.

The specimens prepared in this manner were wrapped in cellophane for $24 \mathrm{hrs}$ and then subjected to FFRC and UCS tests. Figure 3.2 shows the impact of the variation in moisture content on FFRC modulus and UCS for all materials. For all materials, the modulus decreases as the moisture content increases even though the densities of the specimens were more or less the same. The ratios of the moduli at the driest and wettest states vary by as low as 2 for the clay to 
as high as 17 for the high-fine content granular base. The strengths exhibit somewhat different patterns. For the clay and sand, the strength follows the same pattern as modulus. However, for the two bases, the strength does not seem to be very sensitive to moisture, except for wet of OMC.

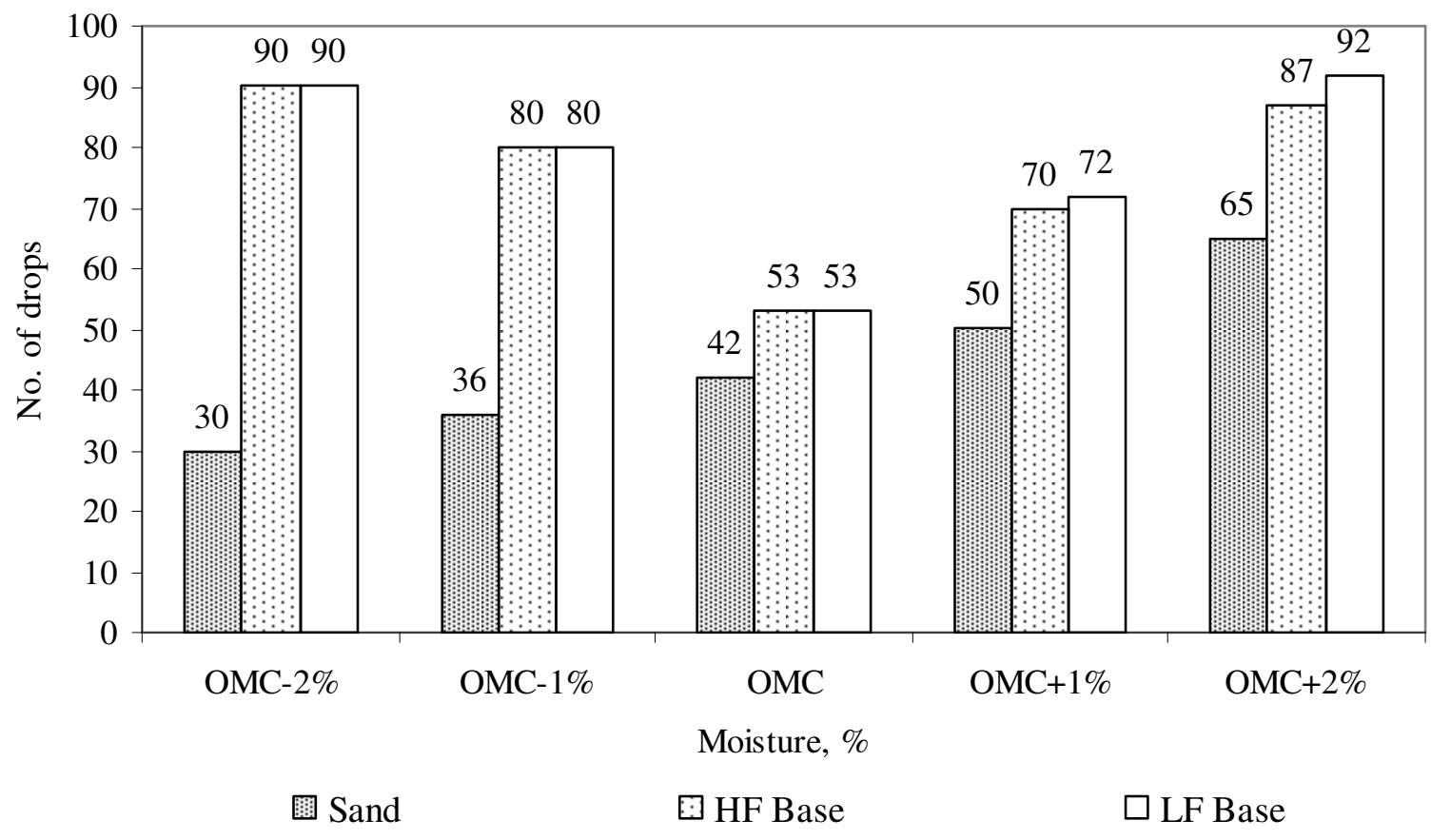

Figure 3.1 - Number of drops vs. moisture content variation comparison

\section{2 - Impact of Moisture at Time of Acceptance relative to Moisture at Compaction}

Even though this has not been an issue with the density-based processes, as the time between the compaction and acceptance is extended, the compacted layer tends to dry, which may impact its strength parameters. Also, it is customary for some highway agencies to conduct the quality acceptance after the material is "cured" (i.e. dried back to moisture content below OMC (e.g., OMC-2\% in Texas). To simulate this situation, several specimens from each material were prepared at the optimum moisture content (OMC), dry of OMC and wet of OMC. These in 

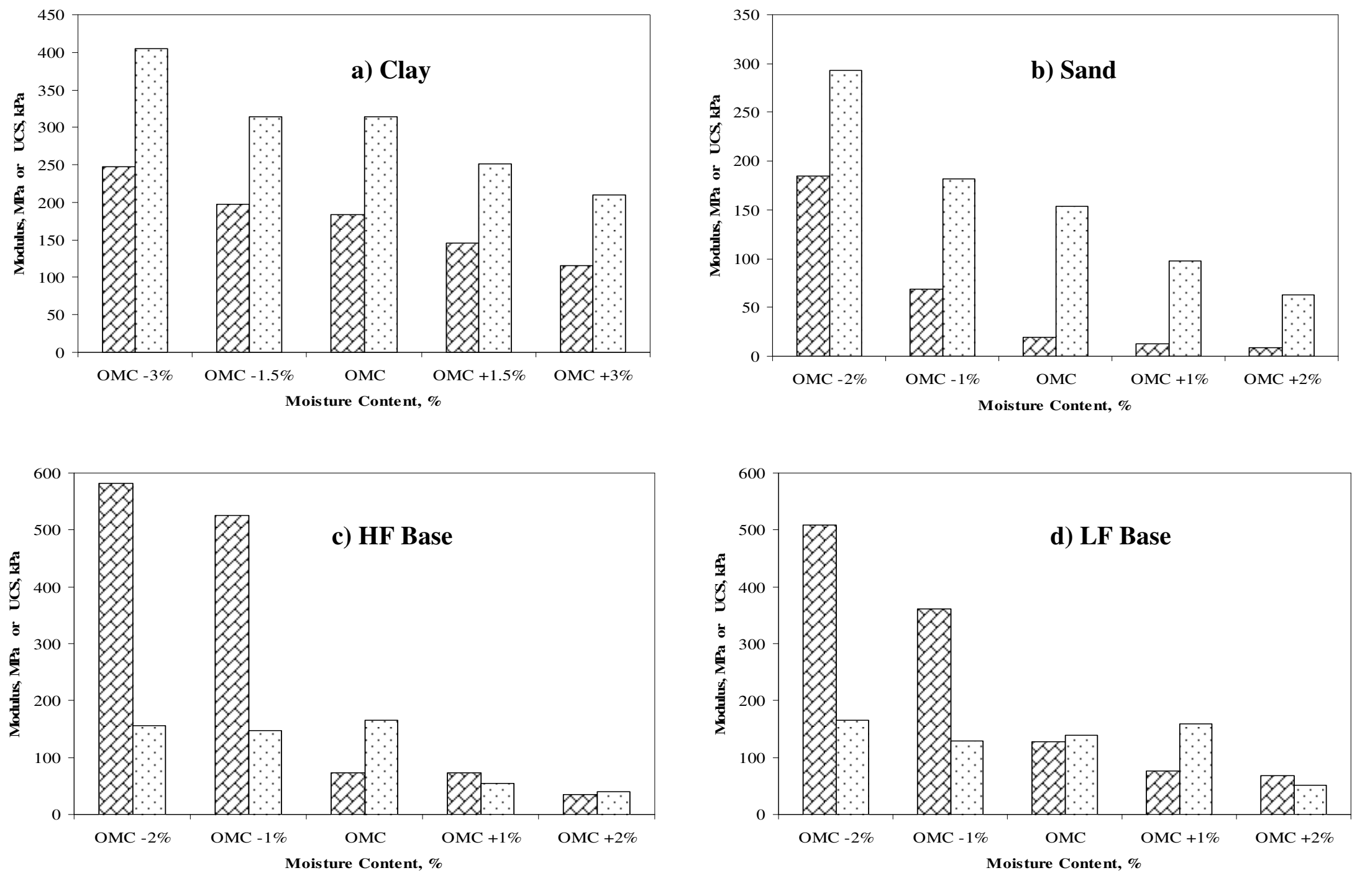

घ Modulus, $\mathrm{MPa}$

$\square \mathrm{UCS}, \mathrm{kPa}$

Figure 3.2 - Impact of Moisture Variation on Modulus and Strength at time of Compaction 
specimens were then allowed to dry to OMC-3\% and OMC-1.5\% for the Clay and Sand, and OMC- $2 \%$ and $\mathrm{OMC}-1 \%$ for the two granular bases at room temperature $\left(25^{\circ} \mathrm{C}\right)$ and at $40^{\circ} \mathrm{C}$ an oven. As soon as the desired moisture was achieved the specimens were subjected to UCS tests.

Figure 3.3 shows the modulus and strength variations for drying the specimens from compaction moisture contents to OMC-1.5\% and OMC-3\% for the Clay. The modulus and strength of the specimens dried at $40^{\circ} \mathrm{C}$ were slightly less than the specimens dried at room temperature for this and other three materials. As such only the results from drying in room temperature are shown hereafter. In general, the further the compaction and acceptance moisture contents are the higher the strength and modulus at acceptance will be. This increase can be as much as 1.5 times. It seems that drying back the specimens compacted at the OMC or below does not seem to impact the results as significantly as those compacted wet of optimum. Also it seems that for setting targets, it would be desirable to compact the specimens at the acceptance moisture content to a target density of MDD.

Figure 3.4 shows the modulus and strength variations with compaction moisture content for the Sand. Modulus for drying back the specimens to OMC-1.5\% is significantly impacted by the compaction moisture content. However, UCS is more or less constant because the specimens become so brittle that they yield in almost an explosive mode. For the dry back moisture of OMC-3\%, both the modulus and strength is less impacted because of the specimens were so dry and brittle.

A similar trend is shown for the base material when dried to OMC-1\% see Figures 3.5 and 3.6. 


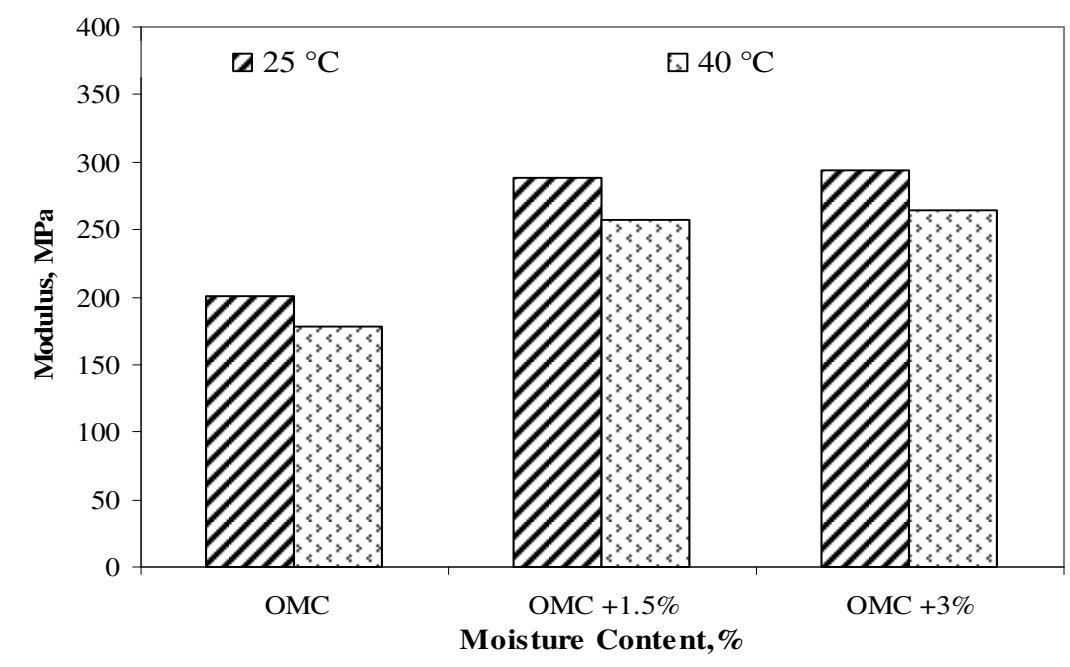

a) Modulus of specimens dried to OMC-1.5\%

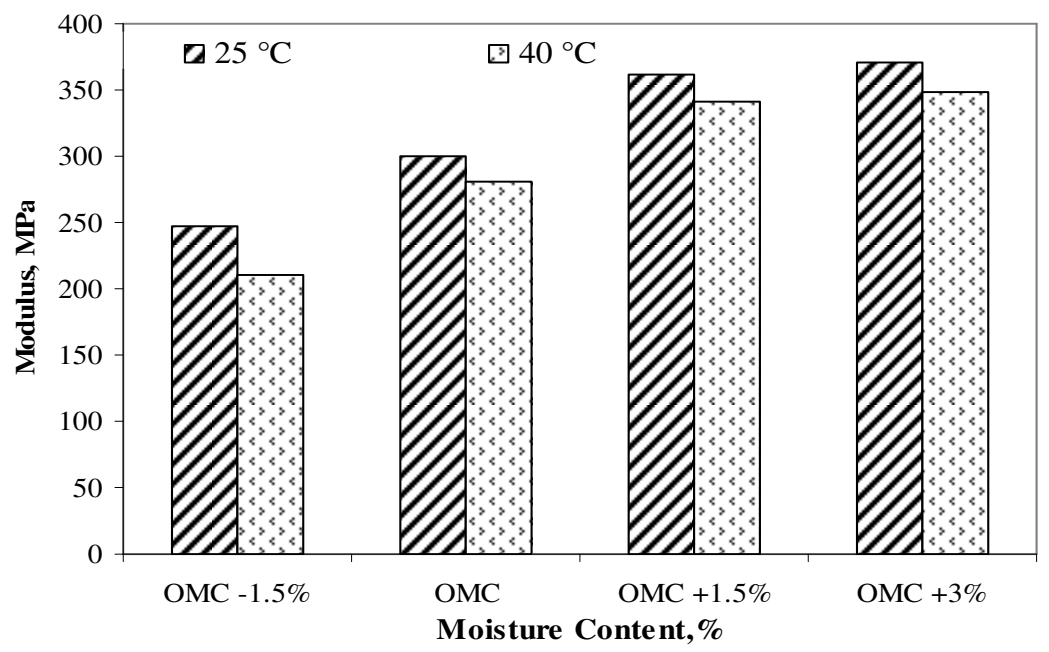

c) Modulus of specimens dried to OMC-3\%

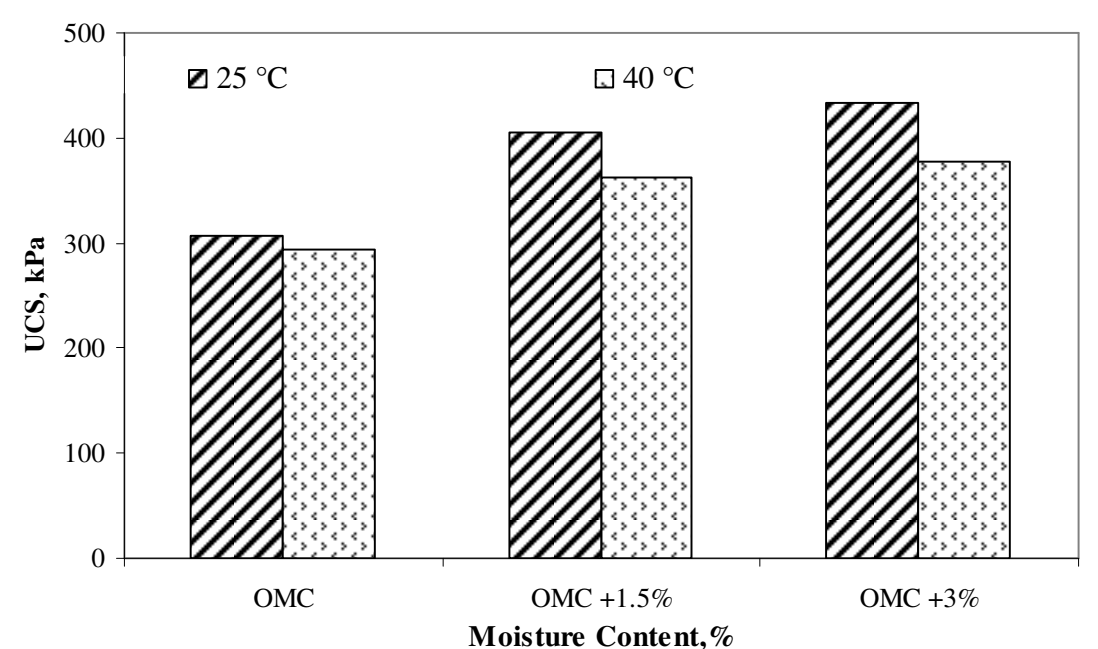

b) UCS of specimens dried to OMC-1.5\%

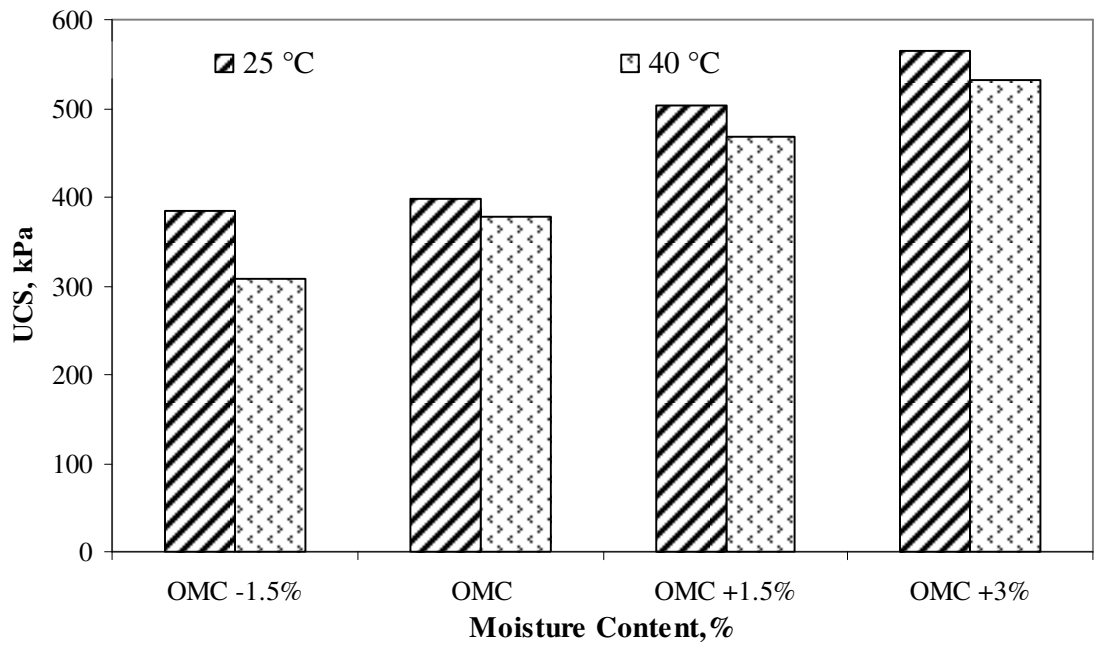

d) UCS of specimens dried to OMC-3\%

Figure 3.3 - Modulus and Strength Variation at Time of Acceptance for Clay Material 

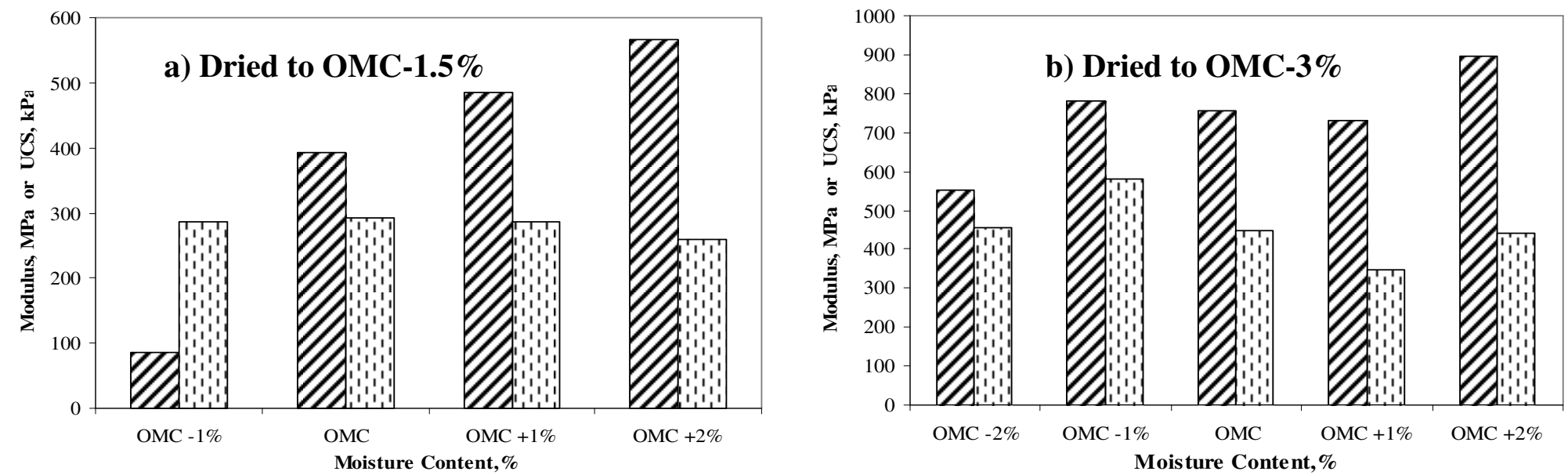

Figure 3.4 - Sand Comparison
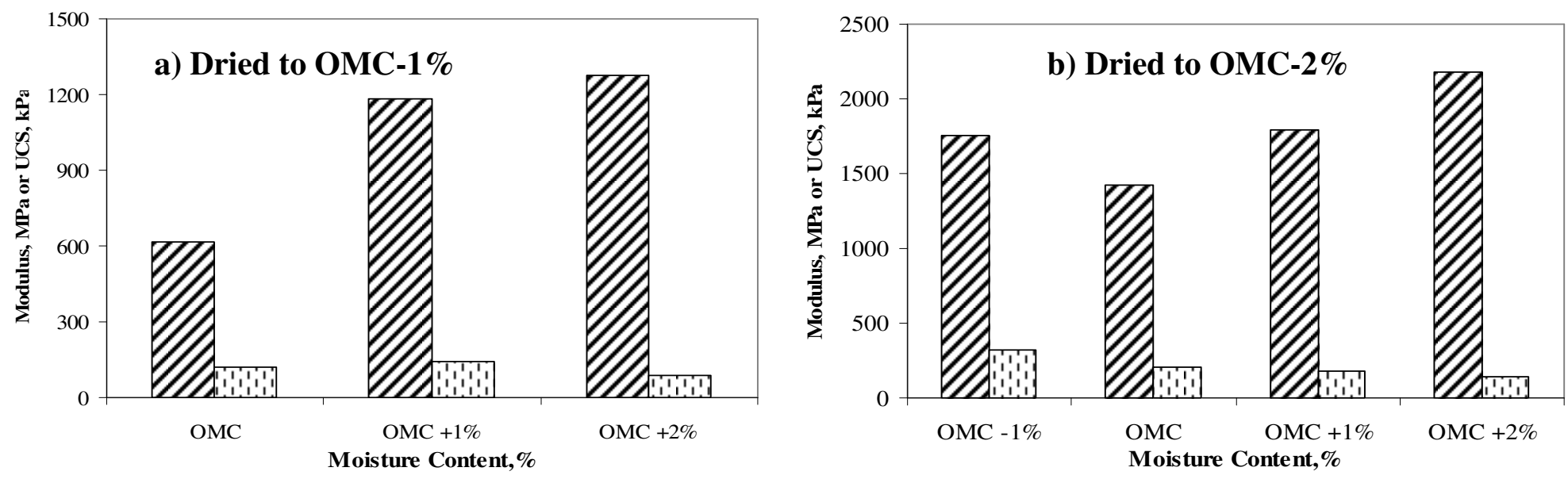

$\square$ Modulus

[. UCS

Figure 3.5 - Modulus and Strength Variation at Time of Acceptance for High-Fine Base 

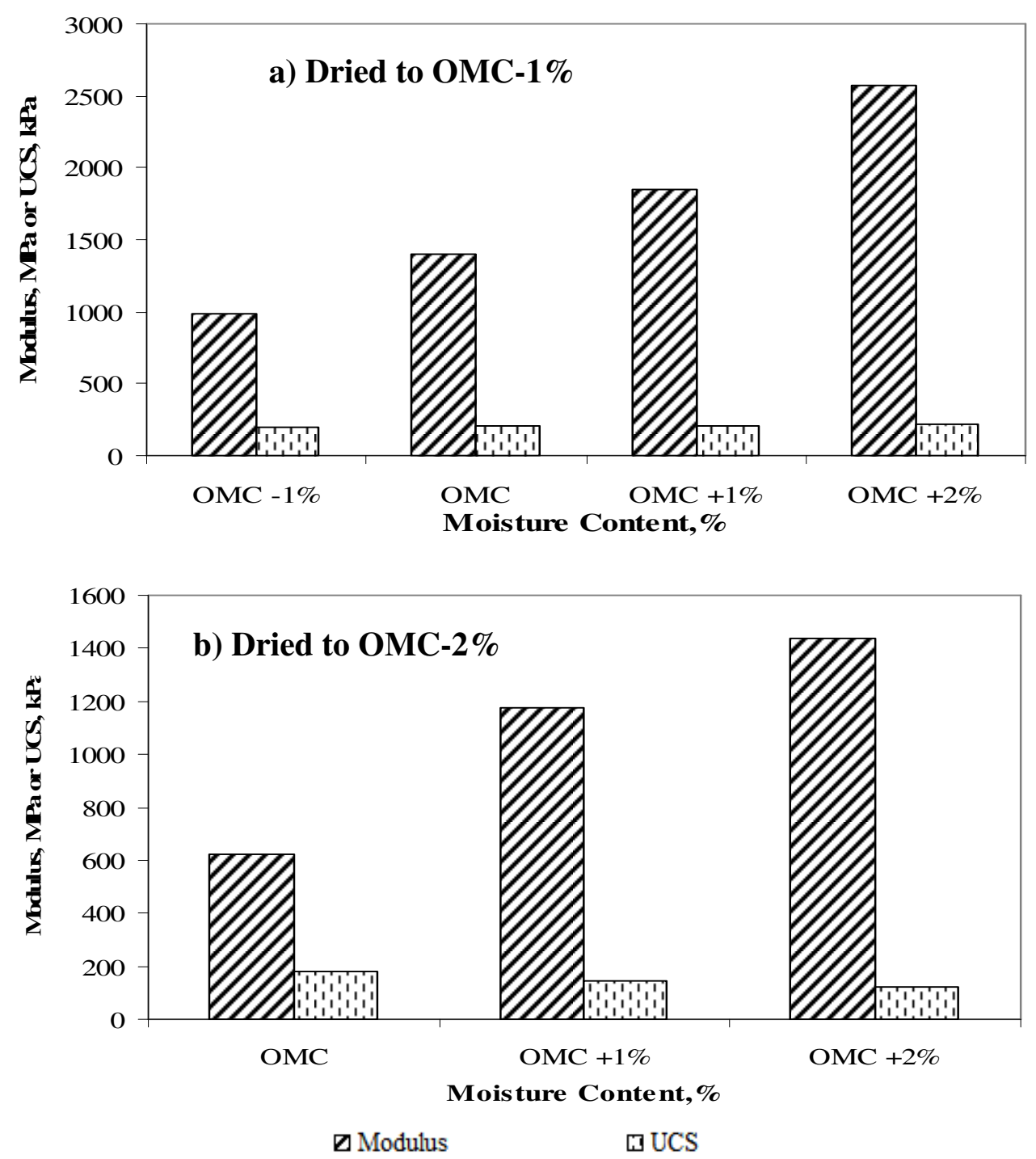

Figure 3.6 - Modulus and Strength Variation at Time of Acceptance for Low-Fine Base

\section{3 - Impact of Density}

Several specimens from each material were prepared at relative densities of $100 \%, 98 \%$, and 96\%. All specimens, irrespective of the density, were compacted at OMC by changing the compaction energy through trial and error. Number of drops vs. density graphs per material is presented on Figure 3.7 (except for the Clay material which was compacted in a Static Compactor). For the Sand material the number of hammer drops increased exponentially. A linear trendline was developed by High-Fine Base; however Low-Fine Base did not show a 
trendline. These specimens were subjected to the UCS and modulus with the FFRC device. Figure 3.8 shows the impact of density variations. For the high-PI Clay as density increased modulus and Strength increased too. On the other hand for the non-plastic materials used in this study as density was increased strength increased too, however a drop in modulus occurred.

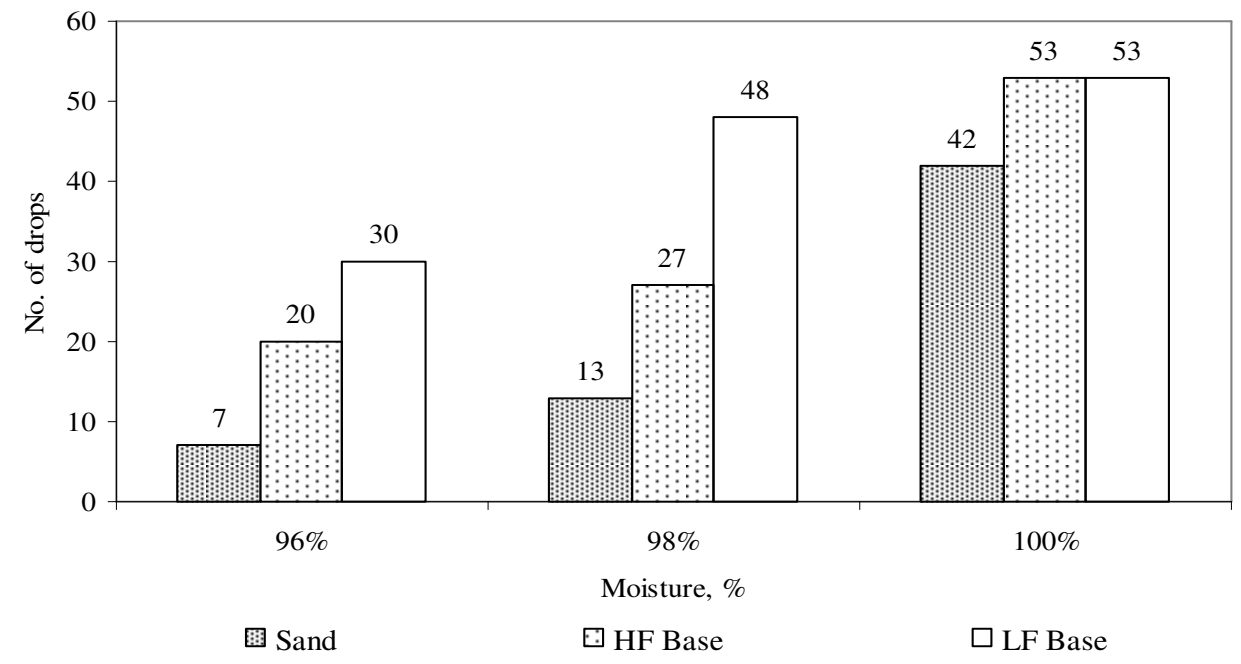

Figure 4- Number of drops comparison for the Geomaterials Used in this Study 

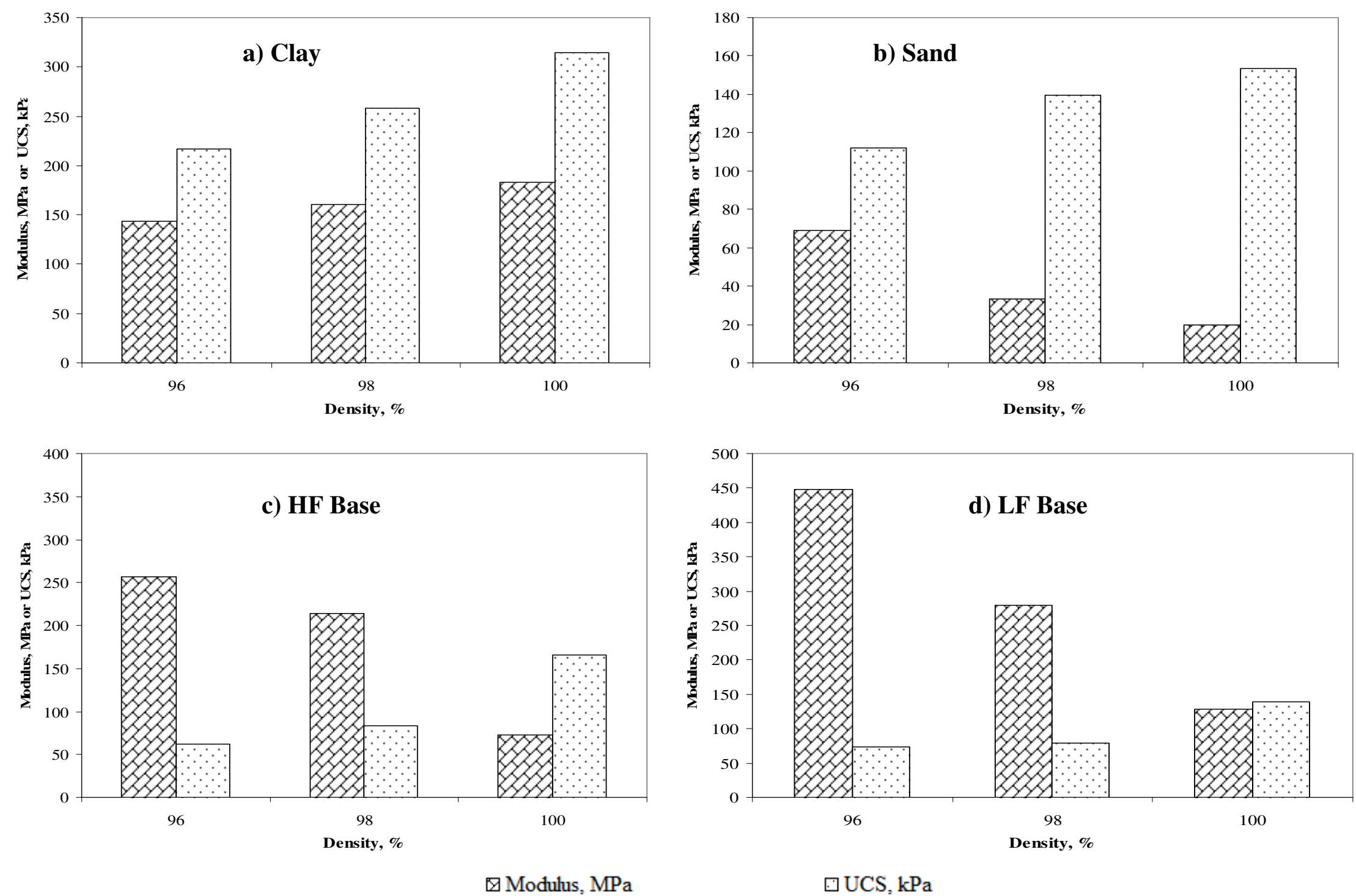

Figure 5 - Impact on Modulus and Strength with Density Variation for the Geomaterials Used in this Study 


\section{Chapter 4: Conclusions}

To evaluate the impact of moisture and density on base and subgrade materials, a number of laboratory tests were performed on three materials consisting of two subgrades and one base. The subgrades were Clay and Sand, while the base was a studied at two different gradations High-Fines Content, and Low-Fines Content.

The variations in modulus, strength with moisture and density deviations were evaluated. Based on the knowledge gained so far, the following observations can be made:

- Under constant compactive effort, the maximum modulus occurs at moisture content less than the optimum moisture content.

- For a constant maximum dry density, as moisture content increases a drop in modulus occurs.

- Strengths of specimens dried at $40^{\circ} \mathrm{C}$ were consistently less than those dried at room temperature.

- Strengths of specimens dried to OMC-1\% for base material and OMC-1.5\% for subgrade materials were consistently lower than those dried to OMC-2\% for base material and OMC-3\% for subgrade materials.

- For High-PI Clay, as the density increases the strength increases too, while for Sand and Base materials as the density increases the strength also increases, however Young's modulus decreases.

- Comparing both base gradations, Finer gradation (HF Base) dries faster than Coarser gradation (LF Base). 


\section{References}

Brown, S. F., and Chan, F. W. K., (1996), Reduced Rutting in Unbound Granular Pavement Layers Through Improved Grading Design. Proc. Instn. Civ. Engrs Transp.

Kong, L. W. and Tan, L. R., (2000), Study on shear strength and swelling-shrinkage characteristic of compacted expansive soil. Unsaturated Soils for Asia. Balkema, Rotterdam, pp 515-519.

Ksaibati, K., Armaghani, J., Fisher, J. (2000), Effect of Moisture on the Modulus Values of Base and Subgrade Materials. National Research Council, Transportation Research Board, Washington, D.C., 2000.

Lambe, T. W. and Whitman, R. W. (1979), Soil Mechanics, John Wiley and Sons, New York, p. 553.

Michaels, A.S. (1959), Discussion to Physico-chemical Properties of Soils: Soil-water Systems, by I. Th. Rosenqvist, ASCE Proceedings. Journal of Soil Mechanics and Foundation Engineering Division, 85, SM2, 91-102.

National Cooperative Highway Research Program (2000), Performance Related Tests of Aggregates for Use in Unbound Pavement Layers, Final Report of Project 4-23, National Research Council.

Scullion, T., and Saaranketo, T. (1997), Using Suction and Dielectric Measurements as Performance Indicators for Aggregate Base Materials. Transportation Research Board, Washington D.C., 2003.

Thom, N. H. and Brown, S.F. (1987), Effect of Moisture on the Structural Performance of a Crushed-Limestone Road Base. National Research Council, Transportation Research Board Washington D.C., 1987.

Thom, N.H. and Brown, S.F. (1988), The Effect of Grading and Density on the Mechanical Properties of a Crushed Dolomitic Limestone. Proc. Aust. Road Res. Board, Canberra, 1988.

Yuan, D., and Nazarian, S. (2003), Variation in Moduli of Base and Subgrade with Moisture. Transportation Research Board D.C., 2003. 


\section{Vita}

Lourdes Pacheco was born on June 30, 1984 in Cd. Juarez, Chihuahua, Mexico. She is the youngest child of two of Enrique Pacheco Aguirre and Maria Altagracia Fernandez Aguirre. She graduated from ITESM Campus Cd. Juarez High School in Cd. Juarez, Chihuahua, Mexico in Spring 2002 and entered the University of Texas at El Paso in Fall 2003 after an exchange program for Rotary International Club in Sao Paulo, Brazil. While pursuing her Bachelors of Science in Civil Engineering, she worked for Federal Highway Administration (FHWA) in the summer of 2006. In the Spring of 2009 she entered the graduate school at the University of Texas at El Paso. While pursuing her graduate degree she worked as a Research Assistant at the Center for Transportation Infrastructure Systems (CTIS) and as a Teaching Assistant for the undergraduate Basic Engineering Mechanics I course and Geotechnical Engineering course. She was the recipient of the Eisenhower Transportation Fellowship in the 2007-2010 academic years.

Permanent address:

Av. Lopez Mateos \#1336 Sur.

Col. Magisterial

Cd. Juarez, Chih. MX

32350

This thesis was typed by Lourdes G. Pacheco. 